\title{
Collateral Sprouting of Uninjured Primary Afferent A-Fibers into the Superficial Dorsal Horn of the Adult Rat Spinal Cord after Topical Capsaicin Treatment to the Sciatic Nerve
}

\author{
Richard J. Mannion, ${ }^{1}$ Tim P. Doubell, ${ }^{1}$ Richard E. Coggeshall, ${ }^{2}$ and Clifford J. Woolf ${ }^{1}$ \\ ${ }_{1}^{1}$ Department of Anatomy and Developmental Biology, University College London, London WC1E 6BT, United Kingdom, \\ and ${ }^{2}$ Department of Anatomy and Neurosciences, Marine Biomedical Institute, The University of Texas Medical Branch, \\ Galveston, Texas 77555-1069
}

That terminals of uninjured primary sensory neurons terminating in the dorsal horn of the spinal cord can collaterally sprout was first suggested by Liu and Chambers (1958), but this has since been disputed. Recently, horseradish peroxidase conjugated to the $B$ subunit of cholera toxin (B-HRP) and intracellular HRP injections have shown that sciatic nerve section or crush produces a long-lasting rearrangement in the organization of primary afferent central terminals, with A-fibers sprouting into lamina II, a region that normally receives only $\mathrm{C}$-fiber input (Woolf et al., 1992). The mechanism of this A-fiber sprouting has been thought to involve injury-induced C-fiber transganglionic degeneration combined with myelinated A-fibers being conditioned into a regenerative growth state.

In this study, we ask whether C-fiber degeneration and A-fiber conditioning are both necessary for the sprouting of A-fibers into lamina II. Local application of the C-fiber-specific neurotoxin capsaicin to the sciatic nerve has previously been shown to result in $\mathrm{C}$-fiber damage and degenerative atrophy in lamina II. We have used B-HRP to transganglionically label A-fiber central terminals and have shown that 2 weeks after topical capsaicin treatment to the sciatic nerve, the pattern of $\mathrm{B}-\mathrm{HRP}$ staining in the dorsal horn is indistinguishable from that seen after axotomy, with lamina II displaying novel staining in the identical region containing capsaicin-treated $\mathrm{C}$-fiber central terminals.

These results suggest that after C-fiber injury, uninjured A-fiber central terminals can collaterally sprout into lamina II of the dorsal horn. This phenomenon may help to explain the pain associated with C-fiber neuropathy.

Key words: regeneration; pain; plasticity; sensory neuron; injury; C-fiber
Collateral sprouting can be defined as the growth of intact axons into neighboring denervated territory. Partial denervation, as a result of nerve lesions, results in the collateral sprouting of both small (Diamond et al., 1992) and large (Doubleday and Robinson, 1994) intact primary sensory axons in the periphery (Kinnman, 1987). Centrally, however, collateral sprouting of primary afferents has been long disputed. In 1958, Liu and Chambers presented data from Golgi studies and suggested that central axons of intact sensory neurons sprouted into regions of dorsal horn denervated by section of adjacent dorsal roots. Since then, the notion that denervation alone is sufficient to induce sprouting of the central axons of uninjured primary sensory neurons has been both supported (Murray and Goldberger, 1986; Polistina et al., 1987; Wang et al., 1987; LaMotte et al., 1989; McNeill et al., 1990, 1991; LaMotte and Kapadia, 1993) and disputed (Rodin and Kruger, 1984; Seltzer and Devor, 1984; Molander et al., 1988; Pubols and Bowen, 1988; McMahon and Kett-White, 1991).

It is clear, however, that central axons of primary sensory neurons conditioned by a cut or crush lesion of their peripheral axons undergo significant central growth, both into peripheral nerve grafts

\footnotetext{
Received April 4, 1996; revised May 30, 1996; accepted June 3, 1996.

This work was supported by the Medical Research Council, National Institutes of Health (NS11255 and NS10161), and the European Union. We thank Jacqueta Meredith-Middleton for technical assistance.

Correspondence should be addressed to Clifford J. Woolf, Department of Anatomy and Developmental Biology, University College London, London WC1E 6BT, UK.

Copyright (C) 1996 Society for Neuroscience $0270-6474 / 96 / 165189-07 \$ 05.00 / 0$
}

(Richardson and Issa, 1984; Richardson and Verge, 1986) and into partially denervated neighboring territories outside normal projection fields (Molander et al., 1988; McMahon and Kett-White, 1991). Peripheral nerve injury also results in a rearrangement of the highly ordered laminar termination of primary afferents within somatotopically appropriate regions of the dorsal horn (Woolf et al., 1992). Large myelinated mechanoreceptive $\mathrm{A} \beta$ fibers normally terminate in lamina III-VI, small myelinated nociceptive A $\delta$ fibers in laminae I and $\mathrm{V}$, and small unmyelinated nociceptive C-fibers in lamina II (substantia gelatinosa) (Brown, 1981; Molander et al., 1984; Molander and Grant, 1985; Willis and Coggeshall, 1991). After injury, however, using $\mathrm{B}$ fragment of cholera toxin conjugated to horseradish peroxidase (B-HRP) to selectively label myelinated fibers (Robertson and Grant, 1985; Rivero-Melian and Grant, 1990; Robertson et al., 1991), peripheral axotomy has been shown to cause longlasting sprouting of A-fibers into lamina II, an area in which they do not normally terminate (Woolf et al., 1992; Koerber et al., 1994; Woolf et al., 1995). Intracellular injections have shown that at least some of these fibers are $\mathrm{A} \beta$ afferents from lamina III (Woolf et al., 1992; Shortland and Woolf, 1993; Koerber et al., 1994).

The A-fiber sprouting into lamina II after peripheral nerve injury is thought to result from a combination of two phenomena (Woolf et al., 1995). The first is the presence of vacant synaptic sites within the superficial dorsal horn as a consequence of transganglionic degeneration (Arvidsson et al., 1986; Kapadia and LaMotte, 1987; Himes and Tessler, 1989) or atrophy (KnyiharCsillik et al., 1987; Castro-Lopes et al., 1990) of unmyelinated C-fibers. The second is the induction of a regenerative capacity in 
the injured neurons (Skene, 1989), presumably because of upregulation of developmentally regulated growth-related proteins such as GAP-43 (Chong et al., 1992). GAP-43 is transported to central terminals of injured sensory neurons in lamina II (Woolf et al., 1990), which is the region that contains novel transganglionic B-HRP labeling (Woolf et al., 1995). Therefore, peripheral nerve injury may induce both the molecular machinery necessary for growth and provide a denervated area for the sprouts to grow into. This type of growth has been termed conditioned collateral sprouting (Woolf et al., 1995).

In this study, we have tried to determine whether A-fibers can collaterally sprout into partially denervated regions of lamina II without a conditioning stimulus to their peripheral axons. Topical nerve treatment with capsaicin, a C-fiber-specific neurotoxin, has been shown to cause transganglionic degeneration exclusively within the C-fiber population of primary afferents (Jancso and Lawson, 1990; Pini et al., 1990; Jancso, 1992) without injuring A-fibers (Wall and Fitzgerald, 1981; Fitzgerald, 1983). We have mapped the distribution of sciatic A-fibers in the dorsal horn with B-HRP to assess whether A-fiber central terminals sprout into lamina II after topical capsaicin treatment.

\section{MATERIALS AND METHODS}

Adult male Sprague Dawley rats (150-200 gm, $n=24)$ were anesthetized with halothane (induction $4 \%$ and maintenance $2.5 \%$ ).

Surgical procedures. The left sciatic nerve was exposed at mid-thigh level under sterile conditions, and plastic film was placed underneath the nerve to isolate it from surrounding tissues $(n=24)$. Cotton wool pledgets soaked in either $1.5 \%$ capsaicin (Sigma, St. Louis, MO) in olive oil $(n=12)$ or olive oil alone (sham-operated animals; $n=10)$ were applied to a $1 \mathrm{~cm}$ length of nerve for $20 \mathrm{~min}$ before being removed. In two animals, the sciatic nerve was axotomized and the proximal stump was ligated without any capsaicin or sham treatment. Overlying muscle and skin were then sutured in two layers, and the animals were left to recover.

Thiamine monophosphatase histochemistry. One week after surgery, two capsaicin-treated animals were terminally anesthetized with $1.6 \mathrm{gm} / \mathrm{kg}$ sodium pentobarbitone and perfused with $200 \mathrm{ml}$ of saline followed by 11 of ice-cold $4 \%$ paraformaldehyde in $0.1 \mathrm{M}$ phosphate buffer, $\mathrm{pH}$ 7.4. L6-L3 segment boundaries were identified from their dorsal roots and marked with vertical midline pins. The lumbar cord was removed and 50 $\mu \mathrm{m}$ transverse sections were cut on a freezing microtome and placed free-floating in individual wells in $0.1 \mathrm{M}$ phosphate buffer before being mounted on gelatin-coated slides and air dried for $1 \mathrm{hr}$. The dried sections were then incubated for $90 \mathrm{~min}$ at $37^{\circ} \mathrm{C}$ in $0.25 \%$ thiamine monophosphate chloride and $0.08 \%$ lead nitrite in $0.04 \mathrm{M}$ Tris-maleate buffer, $\mathrm{pH} 5.6$, rinsed in $0.04 \mathrm{~m}$ Tris-maleate buffer, and developed in $1 \%$ aqueous ammonium sulfide. Sections were rinsed in water and coverslipped using glycerine jelly.

Electron microscopy. Two weeks after surgery, two capsaicin-operated and two sham-operated animals were terminally anesthetized (as above) and perfused with $3 \%$ glutaraldehyde, $3 \%$ paraformaldehyde, and $0.1 \%$ picric acid in $0.1 \mathrm{M}$ phosphate buffer. The sciatic nerves distal to previous treatment were removed and stored in the same fixative overnight. After several rinses in $0.1 \mathrm{M}$ phosphate buffer, the nerve segments were incubated in $2 \%$ osmium tetroxide for $1 \mathrm{hr}$, rinsed in $0.1 \mathrm{~m}$ phosphate buffer, and dehydrated in a series of graded alcohol solutions before being embedded in an Epon-Araldite mixture. Ultrathin sections were cut with a diamond knife (Diatome, Fort Washington, PA) and mounted on Formvar-covered single-hole grids. Photomicrographs were taken on a Phillips transmission electron microscope.

$B$-HRP labeling. Two weeks after surgery, eight capsaicin-treated animals, eight sham-operated animals, two animals with sciatic nerve section, and two naive animals were anesthetized with halothane. Left sciatic nerves were reexposed and injected with $1 \mu \mathrm{l}$ of B-HRP (List, 1.5\% dissolved in distilled water) proximal to the treatment site. Three days later, the animals were terminally anesthetized (as above) and perfused with $200 \mathrm{ml}$ of saline followed by 11 of $1 \%$ paraformaldehyde and $1.25 \%$ glutaraldehyde in $0.1 \mathrm{M}$ phosphate buffer, $\mathrm{pH}$ 7.4. L6-L3 segmental boundaries were identified, and the lumbar cord was removed. HRP reaction product was visualized using the tetramethyl benzidine tech- nique outlined by Mesulam (1978). Sections were mounted on gelatincoated slides and air dried overnight before being cleared in Histoclear and coverslipped using DPX.

Somatotopic maps. The pattern of labeling in consecutive sections was examined using light microscopy, and the extent of mediolateral labeling in lamina II was drawn on graph paper using a flat-field camera lucida. Because the lateral part of the superficial dorsal horn curves ventrally, a horizontal line would significantly underestimate the true width of lamina II. For this reason, measurements were made along a curved line that followed the contour of lamina II. The mediolateral width of staining in lamina II, along with the distance between the medial border of the dorsal horn and the midline, was plotted as a percentage of the total width of lamina II to standardize the measurements between animals. Measurements from consecutive sections of spinal cord were plotted on graph paper to form a somatotopic map of B-HRP staining in lamina II.

\section{RESULTS}

\section{Local effects of capsaicin treatment}

The morphology and number of myelinated axonal profiles in the sciatic nerve distal to the site of capsaicin treatment was compa-

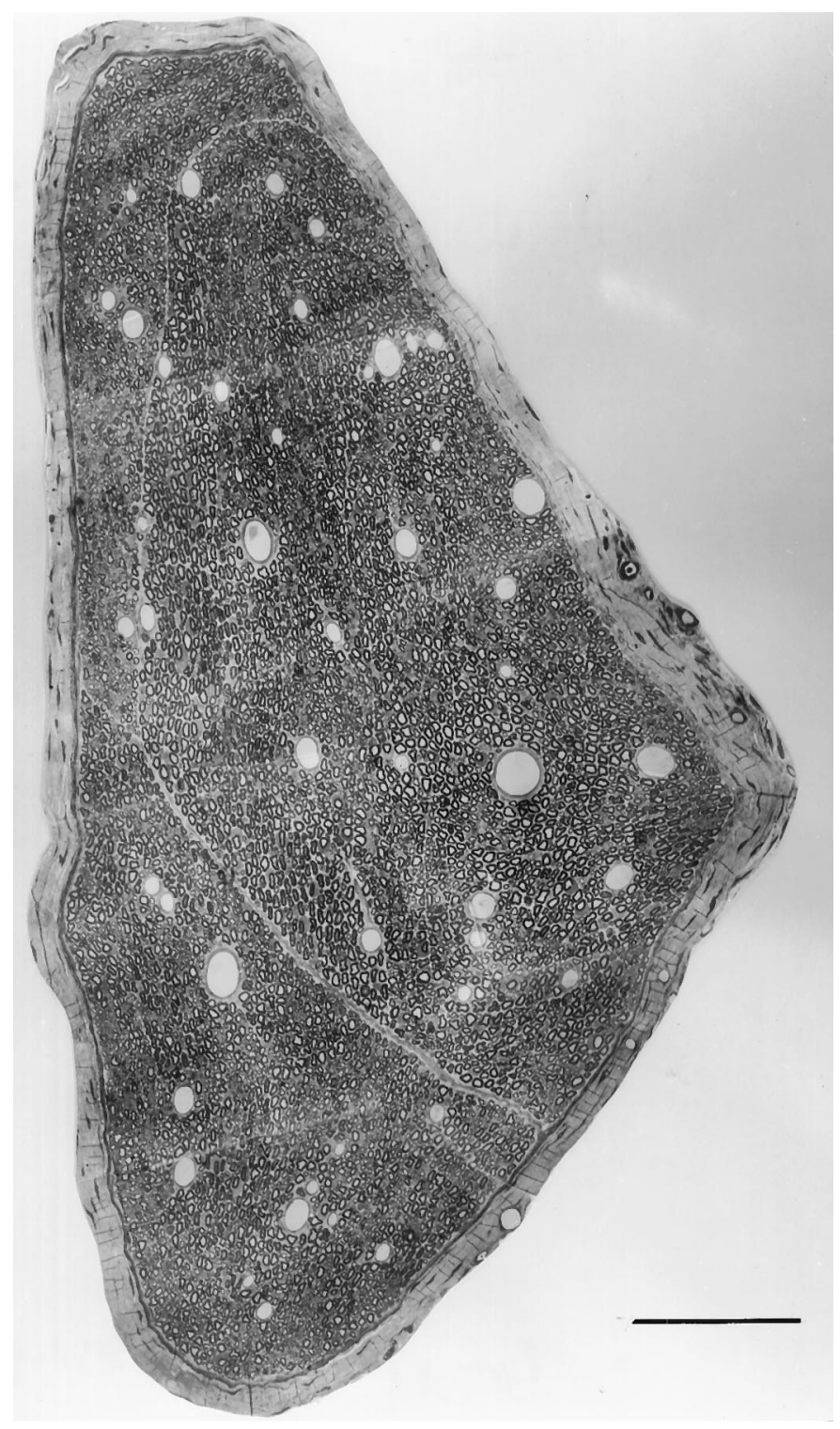

Figure 1. Electron microscopic photomontage of a transverse section through distal sciatic nerve 2 weeks after topical capsaicin treatment. Scale bar, $200 \mu \mathrm{m}$. 
rable to that of sham-treated sciatic nerves (7628 and 8239, respectively), with no evidence whatsoever of Wallerian degeneration in these fibers (Fig. 1).

\section{Central effects of capsaicin treatment: thiamine monophosphatase histochemistry}

Thiamine monophosphatase (TMP) is expressed in a subpopulation of small dorsal root ganglion (DRG) neurons with unmyelinated axons that contain cell surface glycoconjugates recognized by the monoclonal antibody LA4 and the isolectin IB4 (Silverman and Kruger, 1990). The majority of these cells are nonpeptidergic and terminate within lamina II inner (Alvarez et al., 1991). For animals with intact sciatic nerves, TMP labeling was present throughout the full mediolateral extent of lamina II inner in the lumbar spinal cord. After capsaicin treatment of the sciatic nerve, TMP activity was totally depleted in the central field of sciatic C-fibers, which is the medial $1 / 2$ to $3 / 4$ of the lumbar enlargement (Fig. 2).

\section{B-HRP labeling: control}

In the eight sham-operated animals, the labeling pattern of transganglionically transported B-HRP in the dorsal horn of lumbar cord after injection into the sciatic nerve was essentially identical to that seen for naive animals. Widespread staining was observed in all dorsal horn laminae apart from the substantia gelatinosa, lamina II. Staining was evident at the L6/S1 border and extended across the medial three-quarters of lamina III at the L5/L6 segment border (Fig. $3 a$ ). Around the L4/L3 border, a gap appeared in the center of the sciatic nerve labeling that increased in width rostrally (Fig. 3b), representing the central terminals of saphenous nerve afferents (Swett and Woolf, 1985; LaMotte et al., 1991). At no point was there staining in lamina II throughout the length of the lumbar spinal cord.

\section{B-HRP labeling: capsaicin treatment}

The B-HRP labeling in the eight capsaicin-treated animals extended to include lamina II as well as the other dorsal horn laminae (Fig. 3c,d) and was effectively indistinguishable from the B-HRP labeling observed 2 weeks after sciatic nerve transection.

\section{Somatotopic maps}

For the capsaicin-treated animals, the somatotopic distribution of the sprouted B-HRP terminals in lamina II overlapped almost exactly with the zone of TMP depletion (Fig. 4), and no difference was found between the extent and distribution of B-HRP staining in lamina II after axotomy or capsaicin treatment of the sciatic nerve (Fig. 4).

\section{DISCUSSION}

The purpose of this investigation was to determine whether injury to those sensory C-fibers that terminate in lamina II is sufficient to induce collateral sprouting of intact A-fibers, or whether A-fibers must also be primed by peripheral axonal injury, as proposed previously (Woolf et al., 1992, 1995). In this study, we have demonstrated that topical capsaicin treatment to the sciatic nerve results in novel transganglionic B-HRP staining in lamina II. These results suggest either that atrophy restricted to C-fiber terminals in lamina II is sufficient to cause collateral sprouting of uninjured A-fibers into this novel territory or that injured C-fiber terminals release a growth promoting/attractant factor that stimulates intact A-fibers to sprout to the source of the factor in lamina II. This assessment assumes that capsaicin treatment causes toxicity exclusively within the $\mathrm{C}$-fiber population and has no effect on A-fibers. It is therefore important to examine the extent to which capsaicin affects unmyelinated fibers, and whether myelinated A-fibers are affected in any way.

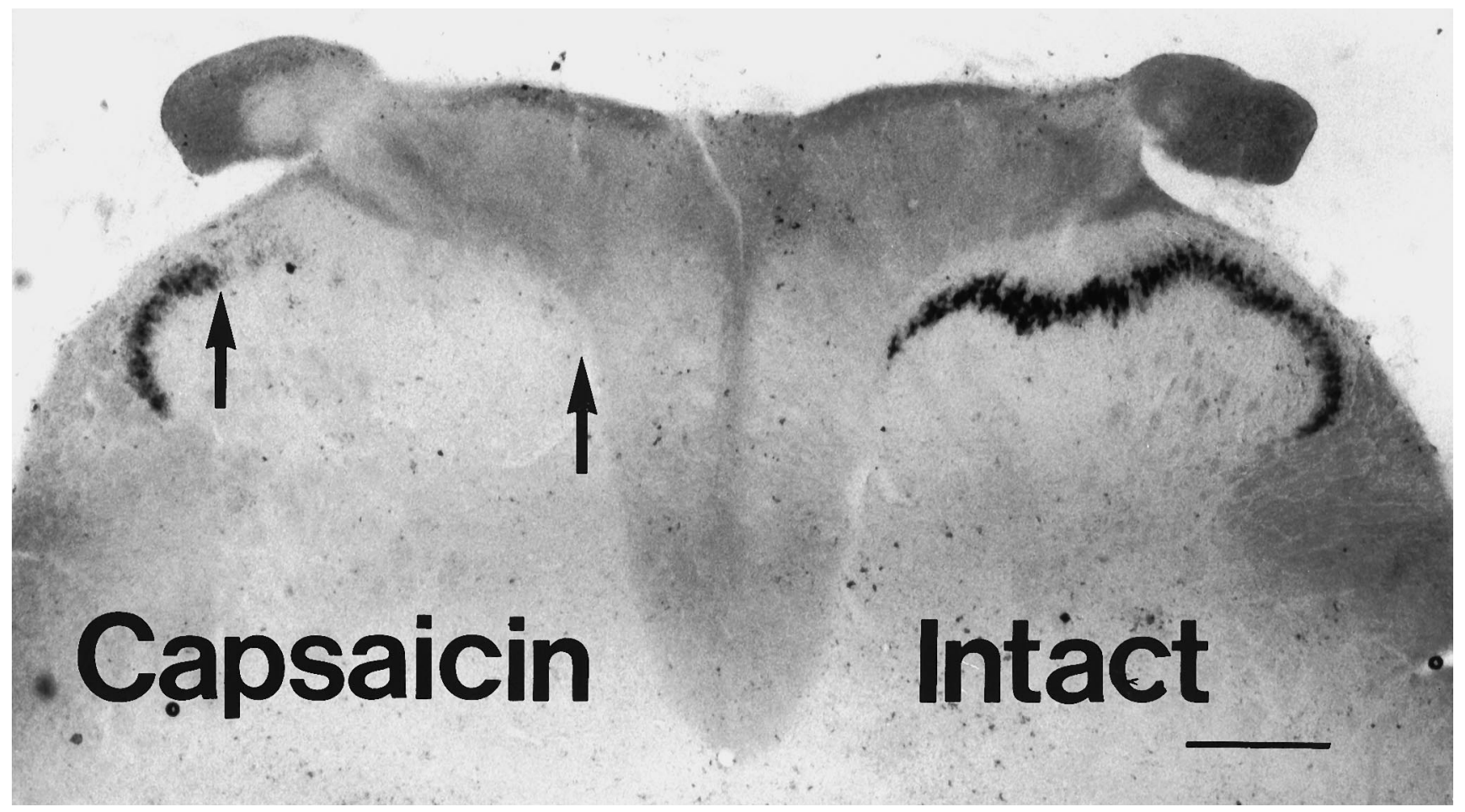

Figure 2. Bright-field photomicrograph of a $50 \mu \mathrm{m}$ transverse section through the spinal cord showing TMP labeling in lamina II of the L5 dorsal horn 1 week after unilateral topical capsaicin treatment to the sciatic nerve. Note the absence of staining of the medial three-quarters of lamina II (arrows) ipsilateral to the treatment. Scale bar, $200 \mu \mathrm{m}$. 


\section{CONTROL}

(a) L5

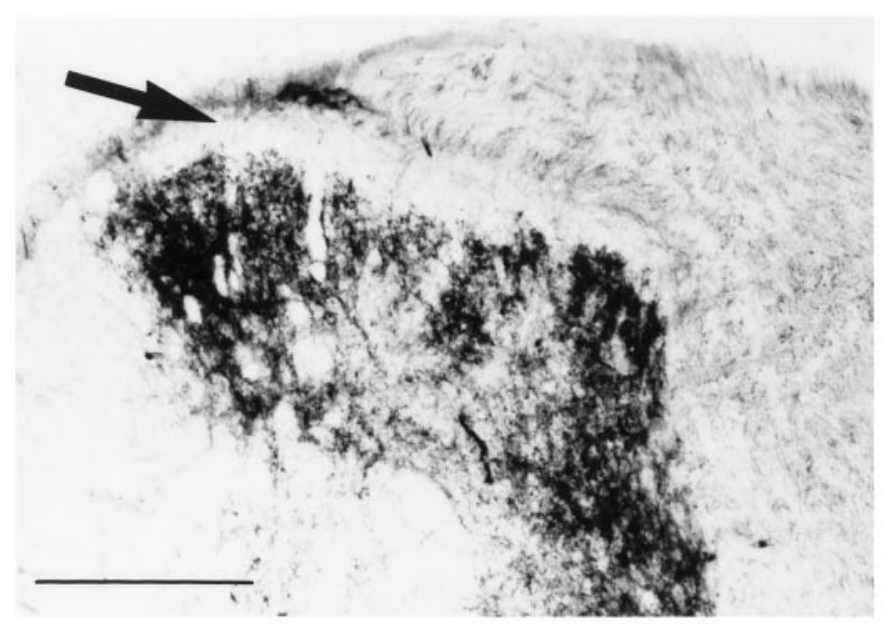

(b) $\mathbf{L 3}$

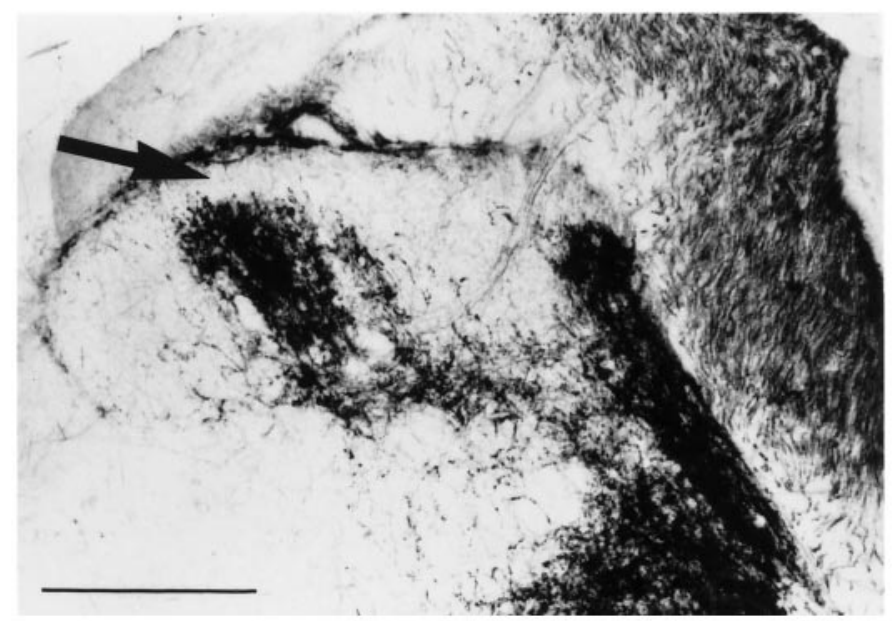

\section{CAPSAICIN}

(c) $\mathbf{L 5}$

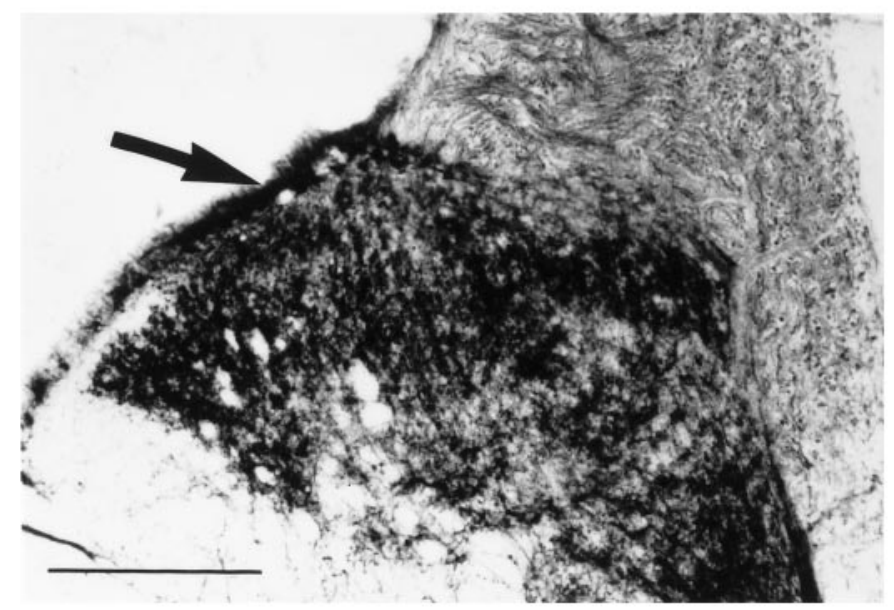

(d) L3

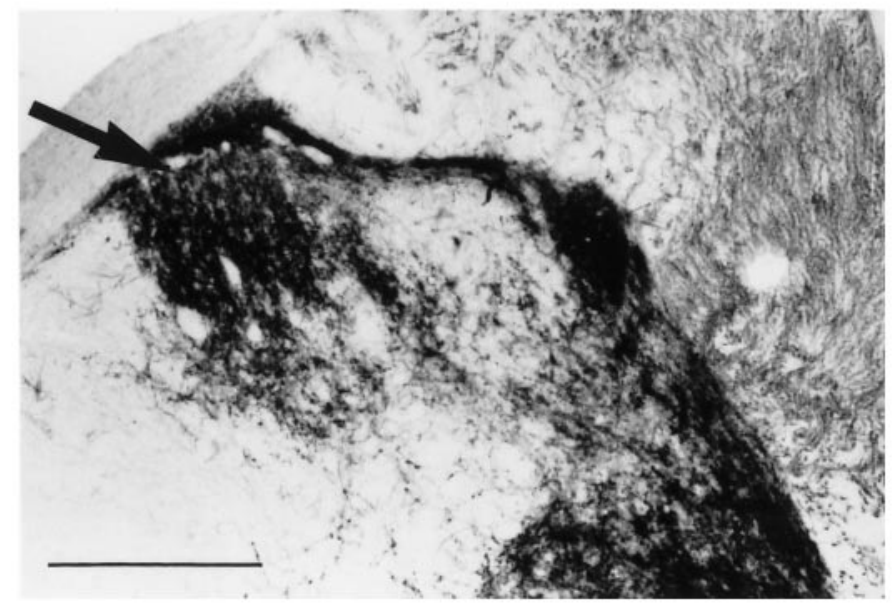

Figure 3. Bright-field photomicrographs of $50 \mu \mathrm{m}$ transverse sections through the dorsal horn showing B-HRP labeling of central terminals of the sciatic nerve in a sham-operated animal at the L5 $(a)$ and L3 $(b)$ level. Note that lamina II is devoid of any B-HRP reaction product (arrows). Territory occupied by saphenous afferent central terminals can be seen to interrupt B-HRP labeling in the center of the dorsal horn in $b$. In a capsaicin-treated animal at L5 (c) and L3 (d), lamina II now displays dense B-HRP staining (arrows). Scale bar, $200 \mu \mathrm{m}$.

As a "specific" toxin for nociceptive C-fibers, capsaicin has been used extensively in pain research, and a "capsaicin-induced analgesia" has been described after various modes of administration (Palermo et al., 1981; Fitzgerald, 1983; Szallasi, 1994). Local application of capsaicin to the sciatic nerve causes an immediate conduction block in C-fibers (Baranowski et al., 1986) and a reduction in the $\mathrm{C}$ - but not the A-fiber component of the compound action potential (Wall and Fitzgerald, 1981; Pini et al., 1990). There is inhibition of axonal transport of substance $P$ and somatostatin, but not norepinephrine (Gamse et al., 1982), showing that capsaicin's action is not on unmyelinated axons per se but on unmyelinated sensory axons. Transganglionic degenerative changes have been described in lamina II after topical capsaicin treatment (Jancso, 1992), which may also explain reduced neuropeptide content within the superficial dorsal horn (Ainsworth et al., 1981; Fitzgerald, 1983), although this could be the consequence of reduced transcription. In the present study, local nerve capsaicin treatment induced a total depletion of TMP in lamina IIi, as found previously (Ainsworth et al., 1981; Gamse et al., 1982). Long-term loss of unmyelinated axons has been detected in the capsaicin-treated nerve, without any evidence of myelinated fiber loss or degeneration (Jancso and Lawson, 1990; Pini et al., 1990) In this study, no Wallerian degeneration or reduction in myelinated fiber numbers was seen. Thus, it seems that the effects of capsaicin, which are thought to be receptor-mediated (Szallasi, 1994), are selective to small afferent fibers (Winter et al., 1995). 


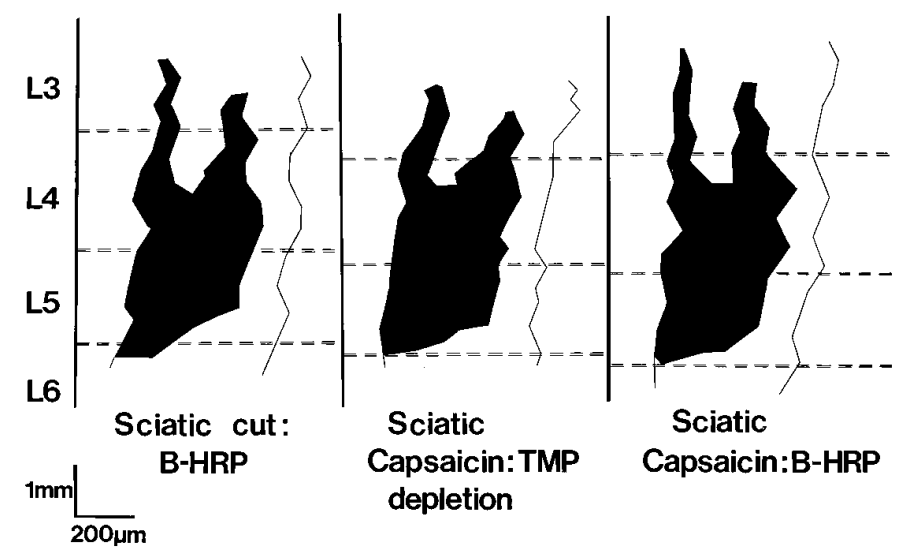

Figure 4. Schematic horizontal map of the somatotopic distribution at the lamina II level in the lumbar enlargement (L3-L6 segments) of B-HRP staining 2 weeks after peripheral axotomy, TMP depletion 1 week after topical capsaicin treatment to the sciatic nerve, and B-HRP staining 2 weeks after topical capsaicin treatment to the sciatic nerve. The pictures are essentially indistinguishable.

It was previously believed that A-fiber sprouting into lamina II was dependent on two conditions: C-fiber injury and A-fiber conditioning (Woolf et al., 1995). The present findings suggest that sprouting can occur after $\mathrm{C}$-fiber injury alone. The signaling mechanism responsible for A-fiber sprouting both after nerve injury and after a neurotoxic injury restricted to C-fibers is unknown, although a number of factors could potentially be involved. Peripheral nerve injury may induce the expression in C-fibers of a factor that induces A-fiber sprouting in the dorsal horn. Peripheral axotomy does change the expression of proteins and peptides in primary sensory neurons (Hokfelt et al., 1994), and the mRNA levels for the neurotrophins nerve growth factor (NGF) and brain-derived neurotrophic factor (BDNF) have been shown to increase in the DRG after peripheral axotomy (Sebert and Shooter, 1993). TrkA, the high-affinity receptor for NGF (Ip et al., 1993; Barbacid, 1994; Kaplan and Stephens, 1994), is expressed in cells with small fibers (DiStefano et al., 1992; Mu et al., 1993; McMahon et al., 1994), whereas the receptor for BDNF, TrkB, is expressed on an intermediate-sized population of DRG cells (Wright and Snider, 1995), possibly those with mechanoreceptive A $\beta$ fibers (Schecterson and Bothwell, 1992; Mu et al., 1993). Interestingly, BDNF upregulation has been found to occur in TrkA-expressing cells after either systemic NGF administration (Apfel et al., 1995) or sciatic nerve section (Verge et al., 1995) (the same cells that will be capsaicin-responsive), and it is conceivable that both nerve injury and capsaicin treatment induce a paracrine signaling between $\mathrm{C}$ and A primary afferents. For example, TrkA-expressing C-fiber cells could release BDNF after nerve injury that acts on TrkB-expressing A-fiber cells to initiate a growth response in the TrkB cells, leading to sprouting of A-fibers in the dorsal horn. This signaling may occur either within the DRG or more likely in the superficial dorsal horn, as neurotrophins can be transported anterogradely as well as retrogradely along axons (von Bartheld et al., 1996). C-fiber central terminals have been shown to release transganglionic tracer into the dorsal horn after nerve injury, which spreads extrasynaptically, a phenomenon that is not observed in uninjured C-fibers (Valtschanoff et al., 1992, 1995).

Alternatively, C-fiber atrophy and loss of input to lamina II may trigger responses within the superficial dorsal horn that initiate
A-fiber sprouting. It is unlikely that vacant synaptic sites would be sufficient to induce growth in distant afferent terminals, but other changes secondary to terminal degeneration may be responsible. Gliosis and an increase in glial fibrillary acidic protein immunoreactivity in the superficial dorsal horn occur after peripheral nerve injury (Hajos et al., 1990) and involve astroglial cell hypertrophy (Gilmore et al., 1990) before morphological reorganization of afferent terminals (Svensson et al., 1993). Similarly, nerve injury results in a rise in the number of microglia in the dorsal horn (Svensson et al., 1993), and the function of these microglia may involve activities other than phagocytosis of degenerating terminals (Knyihar-Csillik et al., 1990). Interestingly, peripheral nerve transection induces an increase in tyrosine phosphorylation in astroglial cells (and to a lesser extent in microglia) that is most prominent in the superficial dorsal horn (Eckert et al., 1994) and which may represent a signaling mechanism from C-fibers to glial cells. C-fibers may release neurotrophic factor(s) that act on neuronal and non-neuronal cells expressing the appropriate trk receptors (Valtschanoff et al., 1995) and may directly or indirectly promote A-fibers to grow into lamina II. At present, it is not possible to quantify the extent of denervation produced by either peripheral axotomy or perineural capsaicin application or determine whether the amount of denervation correlates with the amount of collateral sprouting. Qualitatively, at least, the sprouting produced by complete section of the sciatic nerve and local damage restricted to the $\mathrm{C}$-fiber component of the nerve was indistinguishable.

Whatever the mechanism responsible for initiating A-fiber growth, the demonstration that uninjured A-fibers can sprout into lamina II in response to C-fiber injury is an example of genuine primary afferent collateral sprouting within the adult CNS. The fact that such sprouting results in A-fiber input entering an area of cord that normally only processes C-fiber input may help to explain the pain associated with $\mathrm{C}$-fiber neuropathies. Interestingly, several clinical studies have reported the beneficial use of low-dose capsaicin cream applied to hypersensitive skin in conditions like postherpetic neuralgia (Watson et al., 1993), diabetic neuropathy (Tandan et al., 1992), and trigeminal neuralgia (Fusco and Alessandri, 1992). Because many patients receiving such treatment already have allodynia, it will be difficult to assess whether it introduces a novel neuropathic pain. However, it is unlikely that chronic low-dose capsaicin cream results in an anatomical reorganization in the spinal cord, because a long-term study of the effects of topical, cutaneous, low-dose capsaicin cream application in rats failed to show any of the neuropeptide changes reported after perineural capsaicin treatment (McMahon et al., 1991).

\section{REFERENCES}

Ainsworth A, Hall P, Wall PD, Allt G, Lynn Mackenzie M, Gibson S, Polak JM (1981) Effects of capsaicin applied locally to adult peripheral nerve II: anatomy and enzyme and peptide chemistry of peripheral nerve and spinal cord. Pain 11:379-388.

Alvarez FJ, Morris HR, Priestley JV (1991) Sub-populations of smaller diameter trigeminal primary afferent neurons defined by expression of calcitonin gene-related peptide and the cell surface oligosaccharide recognized by monoclonal antibody LA4. J Neurocytol 20:716-731.

Apfel SC, Wright D, Dormia C, Snider WD, Kessler JA (1995) Nerve growth factor stimulates BDNF mRNA expression in the peripheral nervous system. Soc Neurosci Abstr 419:14.

Arvidsson J, Ygge J, Grant G (1986) Cell loss in lumbar dorsal root ganglia and transganglionic degeneration after sciatic nerve resection in the rat. Brain Res 373:15-21. 
Baranowski R, Lynn B, Pini A (1986) The effects of locally applied capsaicin on conduction in cutaneous nerves in four mammalian species. Br J Pharmacol 89:267-276.

Barbacid M (1994) The trk family for neurotrophin receptors. J Neurobiol 25:1386-1403.

Brown AG (1981) Organization in the spinal cord: the anatomy and physiology of identified neurones, pp 137-150. Berlin: Springer.

Castro-Lopes JM, Coimbra A, Grant G, Arvidsson J (1990) Ultrastructural changes of the central scalloped $(\mathrm{C} 1)$ primary afferent endings of synaptic glomeruli in the substantia gelatinosa Rolandi of the rat after peripheral neurotomy. J Neurocytol 19:329-337.

Chong M-S, Fitzgerald M, Winter J, Hu-Tsai M, Emson PC, Weise U, Woolf CJ (1992) GAP-43 mRNA in rat spinal cord and dorsal root ganglia neurons: developmental changes and re-expression following peripheral nerve injury. Eur J Neurol 4:883-895.

Diamond J, Holmes M, Coughlin MD (1992) Endogenous NGF and nerve impulses regulate the collateral sprouting of sensory axons in the skin of the adult rat. J Neurosci 12:1454-1466.

DiStefano PS, Friedman B, Radziejewesk C, Alexander C, Boland P, Schieck CM, Lindsay RM, Wiegand SJ (1992) The neurotrophins BDNF, NT-3 and NGF display distinct patterns of retrograde axonal transport in peripheral and central neurons. Neuron 8:983-993.

Doubleday B, Robinson PP (1994) NGF depletion reduces collateral sprouting of cutaneous mechanoreceptive and tooth-pulp axons in ferrets. J Physiol (Lond) 481:709-718.

Eckert WA, Valtschanoff JG, Otey CA, Rustioni A, Weinberg RJ (1994) Tyrosine phosphorylation in rat spinal cord after sciatic nerve transection. NeuroReport 5:1289-1292.

Fitzgerald M (1983) Capsaicin and sensory neurones-a review. Pain 15:109-130.

Fusco BM, Alessandri M (1992) Analgesic effect of capsaicin in idiopathic trigeminal neuralgia. Anesth Analg 74:375-377.

Gamse R, Petsche U, Lembeck F, Jancso G (1982) Capsaicin applied to peripheral nerve inhibits axoplasmic transport of substance $\mathrm{P}$ and somatostatin. Brain Res 239:447-462.

Gilmore SA, Sims TJ, Leiting JE (1990) Astrocytic reactions in spinal gray matter following sciatic axotomy. Glia 3:342-349.

Hajos F, Csillik B, Knyihar-Csillik E (1990) Alterations in glial fibrillary acidic protein immunoreactivity in the upper dorsal horn of the rat spinal cord in the course of transganglionic degenerative atrophy and regenerative proliferation. Neurosci Lett 117:8-13.

Himes BT, Tessler A (1989) Death of some DRG neurons and plasticity of others following sciatic nerve section in adult and neonatal rats. J Comp Neurol 284:215-230.

Hokfelt T, Zhang X, Wiesenfeld-Hallin Z (1994) Messenger plasticity in primary sensory neurons following axotomy and its functional implications. Trends Neurosci 17:22-30.

Ip NY, Stitt TN, Tapley P, Klein R, Glass DJ, Fandl J, Greene LA, Barbacid M, Yancopoulos GD (1993) Similarities and differences in the way neurotrophins interact with the trk receptors in neuronal and nonneuronal cells. Neuron 10:137-149.

Jancso G (1992) Pathobiological reactions of C-fibre primary sensory neurones to peripheral nerve injury. Exp Physiol 77:405-431.

Jancso G, Lawson SN (1990) Transganglionic degeneration of capsaicin-sensitive C-fibre primary afferent terminals. Neuroscience 39:501-511.

Kapadia SE, LaMotte CC (1987) Deafferentation induced alterations in the rat dorsal horn. I. Comparison of peripheral nerve injury versus rhizotomy effects on presynaptic, post-synaptic and glial processes. J Comp Neurol 266:183-197.

Kaplan DR, Stephens RM (1994) Neurotrophin signal transduction by the trk receptor. J Neurobiol 25:1404-1417.

Kinnman E (1987) Collateral sprouting of sensory axons in the hairy skin of the trunk: a morphological study in adult rats. Brain Res 414:385-389.

Knyihar-Csillik E, Rakic P, Csillik B (1987) Transganglionic degenerative atrophy in the substantia gelatinosa of the spinal cord after peripheral nerve transection in rhesus monkeys. Cell Tissue Res 247:599-604.

Knyihar-Csillik E, Torok A, Csillik B (1990) Primary afferent origin of substance P-containing axons in the superficial dorsal horn of the rat spinal cord: depletion, regeneration and replenishment of presumed nociceptive central terminals. J Comp Neurol 297:594-612.

Koerber HR, Mirnics K, Brown PB, Mendell LM (1994) Central sprouting and functional plasticity of regenerated primary afferents. J Neurosci $14: 3655-3671$.
LaMotte CC, Kapadia SE (1993) Deafferentation-induced terminal field expansion of myelinated saphenous afferents in the adult rat dorsal horn and the nucleus gracilis following pronase injection of the sciatic nerve. J Comp Neurol 330:83-94.

LaMotte CC, Kapadia SE, Kocol CE (1989) Deafferentation-induced expansion of sciatic terminal field labelling in the adult rat dorsal horn following pronase injection of the sciatic nerve. J Comp Neurol 288:311-325.

LaMotte CC, Kapadia SE, Shapiro CM (1991) Central projections of the sciatic, saphenous, median, and ulnar nerves of the rat demonstrated by transganglionic transport of choleragenoid-HRP (B-HRP) and wheat germ agglutinin-HRP (WGA-HRP). J Comp Neurol 311:546-562.

Liu CN, Chambers WW (1958) Intraspinal sprouting of dorsal root axons. Arch Neurol 79:46-61.

McMahon SB, Kett-White R (1991) Sprouting of peripherally regenerating primary sensory neurones in the adult central nervous system. J Comp Neurol 304:307-315.

McMahon SB, Lewin G, Bloom SR (1991) The consequences of longterm topical capsaicin application in the rat. Pain 44:301-310.

McMahon SB, Armanini MP, Ling LH, Phillips HS (1994) Expression and coexpression of trk receptors in subpopulations of adult primary sensory neurons projecting to identified peripheral targets. Neuron 12:1161-1171.

McNeill DL, Carlton SM, Coggeshall RE, Hulsebosch CE (1990) Denervation-induced intraspinal synaptogenesis of calcitonin generelated peptide containing primary afferent terminals. J Comp Neurol 296:263-268.

McNeill DL, Carlton SM, Hulsebosch CE (1991) Intraspinal sprouting of CGRP-containing primary afferents after deafferentation in the rat. Exp Neurol 114:321-329.

Mesulam MM (1978) Tetramethyl benzidine for horseradish peroxidase neurohistochemistry: a non-carcinogenic blue reaction product with superior sensitivity for visualizing neural afferents and efferents. J Histochem Cytochem 26:106-117.

Molander C, Grant G (1985) Cutaneous projections from the rat hindlimb foot to the substantia gelatinosa of the spinal cord studied by transganglionic transport of WGA-HRP conjugate. J Comp Neurol 237:476-484.

Molander C, Xu Q, Grant G (1984) The cytoarchitectonic organization of the spinal cord in the rat. I. The lower thoracic and lumbosacral cord. J Comp Neurol 230:133-144.

Molander C, Kinnman E, Aldskogius H (1988) Expansion of spinal cord primary sensory afferent projection following combined sciatic nerve resection and saphenous nerve crush: a horseradish peroxidase study in the adult rat. J Comp Neurol 276:436-441.

Mu X, Silos-Santiago I, Carroll SL, Snider WD (1993) Neurotrophin receptor genes are expressed in distinct patterns in developing dorsal root ganglia. J Neurosci 13:4029-4041.

Murray M, Goldberger ME (1986) Replacement of synaptic terminals in lamina II and Clarke's nucleus after unilateral lumbosacral dorsal rhizotomy in adult cats. J Neurosci 6:3205-3217.

Palermo NW, Brown HK, Smith DL (1981) Selective neurotoxic action of capsaicin or glomerular C-type terminals in rat substantia gelatinosa. Brain Res 208:506-510.

Pini A, Baranowski R, Lynn B (1990) Long-term reduction in the number of C-fibre nociceptors following capsaicin treatment of a cutaneous nerve in adult rats. Eur J Neurosci 2:89-97.

Polistina D, Murray M, Goldberger ME (1987) Myelinated fibres contribute to dorsal root sprouting after partial deafferentation in rats. Soc Neurosci Abstr 13:166.

Pubols LM, Bowen DC (1988) Lack of central sprouting of primary afferent fibers after ricin deafferentation. J Comp Neurol 275:282-287.

Richardson PM, Issa VMK (1984) Peripheral injury enhances central regeneration of primary sensory neurones. Nature 309:791-793.

Richardson PM, Verge VMK (1986) The induction of a regenerative propensity in sensory neurons following peripheral axonal injury. J Neurocytol 15:585-594.

Rivero-Melian C, Grant G (1990) Distribution of lumbar dorsal root fibres in the lower thoracic and lumbosacral spinal cord of the rat studied with choleragenoid horseradish peroxidase conjugate. J Comp Neurol 299:470-481.

Robertson B, Grant G (1985) A comparison between wheat germ agglutinin- and choleragenoid-horseradish peroxidase as anterogradely transported markers in central branches of primary sensory neurones in the rat with some observations in the cat. Neuroscience 14:895-905. 
Robertson B, Perry MJ, Lawson SN (1991) Populations of rat spinal primary afferent neurons with choleragenoid binding compared with those labelled by markers for neurofilament and carbohydrate groups: a quantitative immunocytochemical study. J Neurocytol 20:387-395.

Rodin BE, Kruger L (1984) Absence of intraspinal sprouting in dorsal root axons caudal to a partial spinal hemisection: a horseradish peroxidase transport study. Somatosens Mot Res 2:171-192.

Schecterson LC, Bothwell M (1992) Novel roles for neurotrophins are suggested by BDNF and NT-3 mRNA expression in developing neurons. Neuron 9:449-463.

Sebert ME, Shooter EM (1993) Expression of mRNA for neurotrophic factors and their receptors in the rat dorsal root ganglion and sciatic nerve following nerve injury. J Neurosci Res 36:357-367.

Seltzer Z, Devor M (1984) Effect of nerve section in the spinal distribution of neighbouring nerves. Brain Res 306:31-37.

Shortland P, Woolf CJ (1993) Chronic peripheral nerve section results in a rearrangement of the central axonal arborizations of axotomized A beta primary afferent neurons in the rat spinal cord. J Comp Neurol 330:65-82.

Silverman JD, Kruger L (1990) Selective neuronal glycoconjugate expression in sensory and autonomic ganglia: relation of lectin reactivity to eptid and enzyme markers. J Neurocytol 19:789-801.

Skene JHP (1989) Axonal growth associated proteins. Annu Rev Neurosci 12:127-156.

Svensson M, Eriksson P, Pesson JKE, Molander C, Arvidsson Aldskogius H (1993) The response of central glial to peripheral nerve injury. Brain Res Bull 30:499-506.

Swett JE, Woolf CJ (1985) Somatotopic organization of primary afferent terminals in the superficial dorsal horn of the rat spinal cord. J Comp Neurol 231:66-71.

Szallasi A (1994) The vanilloid (capsaicin) receptor: receptor types and nerve differences. Gen Pharmacol 25:223-243.

Tandan R, Lewis GA, Krusinski PB, Badger GB, Fries TJ (1992) Topical capsaicin in painful diabetic neuropathy. Controlled study with longterm follow-up. Diabetes Care 15:8-14.

Valtschanoff JG, Weinberg RJ, Rustioni A (1992) Peripheral injury and anterograde transport of wheat germ agglutinin-horse radish peroxidase to the spinal cord. Neuroscience 50:685-696.
Valtschanoff JG, Weinberg RJ, Rustioni A (1995) Central release of tracer after noxious stimulation of the skin suggests non-synaptic signaling by unmyelinated fibers. Neuroscience 64:851-854.

Verge VMK, Gratto KA, Karchewski LA, Richardson PM (1996) Neurotrophins and sensory neurons-role in development, maintenance, and injury. Philos Trans R Soc Lond Biol 351:423-430.

von Bartheld CS, Byers MR, Williams R, Bothwell M (1996) Anterograde transport of neurotrophins and axodendritic transfer in the developing visual system. Nature 379:830-833.

Wall PD, Fitzgerald M (1981) Effects of capsaicin applied locally to adult peripheral nerve. I. Physiology of peripheral nerve and spinal cord. Pain 11:363-377.

Wang SD, Eckenrode T, Goldberger ME, Murray M (1987) Plasticity of intrinsic and extrinsic systems after rhizotomy of rat spinal cord. Soc Neurosci Abstr 13:166.

Watson CP, Tyler KL, Bickers DR, Millikan LE, Smith S, Coleman E (1993) A randomized vehicle-controlled trial of topical capsaicin in the treatment of postherpetic neuralgia. Clin Ther 15:510-526.

Willis WD, Coggeshall RE (1991) Sensory mechanisms of the spinal cord, pp 79-132. New York: Plenum.

Winter J, Bevan S, Campbell EA (1995) Capsaicin and pain mechanisms. Br J Anaesth 75:157-168.

Woolf CJ, Reynolds ML, Molander C, O'Brien C, Lindsay RM, Benowitz LI (1990) GAP-43 a growth associated protein, appears in dorsal root ganglion cells and in the dorsal horn of the rat spinal cord following peripheral nerve injury. Neuroscience 34:465-478.

Woolf CJ, Shortland P, Coggeshall RE (1992) Peripheral nerve injury triggers central sprouting of myelinated afferents. Nature 355:75-77.

Woolf CJ, Shortland P, Reynolds ML, Ridings J, Doubell TP, Coggeshall RE (1995) Central regenerative sprouting: the reorganization of the central terminals of myelinated primary afferents in the rat dorsal horn following peripheral nerve section or crush. J Comp Neurol 360:121-134.

Wright DE, Snider WD (1995) Neurotrophin receptor mRNA expression defines distinct populations of neurons in rat dorsal root ganglia. J Comp Neurol 351:329-338. 